\section{Commentary: Smoking cessation: No one said it was E-asy}

\author{
Philip W. Carrott, Jr, MD, FACS
}

As a recently graduated Tobacco Treatment Specialist, the intricacies of nicotine addiction and difficulties of ceasing to use nicotine are fresh in my mind. In treating patients for smoking-related diseases, it should be surprising that as providers, thoracic surgeons are not formally instructed on tobacco cessation counseling. I was surprised in particular that my past practice in counseling patients for tobacco cessation was so inadequate. Even prescribing nicotine replacement therapy should be done carefully and with a reasonable plan and instruction on the right and wrong way to use it.

In this issue of the Journal, Dr Steliga outlines much of this in his review of the possible role of E-cigarettes in a smoking cessation plan, which is really quite limited. ${ }^{1}$ E-cigarettes were developed to replace combustible cigarettes, not as an aid to smoking cessation. In fact, the current leading e-cigarette, Juul, is the first to approximate the blood plasma concentrations of nicotine seen in tobacco smokers. It also should be unsurprising that a company marketing nicotine consumption is not interested in helping people quit nicotine. Before the launch of Juul, one of its engineers said, "We don't think a lot about addiction here because we're not trying to design a cessation product at all," he said, later noting that "anything about health is not on our mind.",

In helping patients quit smoking, there is quite a bit of work to do to assess their addiction and then leading them to first cut down their cigarette consumption and eventually stop smoking. Depending on the severity of their addiction, this can take some time or may never occur unless some external pressure can galvanize the desire for change. As thoracic surgeons, we have some of the best opportunities to facilitate this discussion on quitting, and indeed can outline a number of short-term health benefits to surgical recovery that are real, particularly in the context of lung cancer surgery.

\footnotetext{
From the Division of Thoracic Surgery, Baylor St Luke's Medical Center, Houston, Tex.

Received for publication Dec 1, 2020; revisions received Dec 1, 2020; accepted for publication Dec 2, 2020; available ahead of print Dec 9, 2020.

Address for reprints: Philip W. Carrott, Jr, MD, FACS, Division of Thoracic Surgery, Baylor St. Luke's Medical Center, Baylor College of Medicine, 7200 Cambridge St, Ste 6A, Houston, TX 77030 (E-mail: Philip.Carrott@bcm.edu).

J Thorac Cardiovasc Surg 2022;163:311

$0022-5223 / \$ 36.00$

Copyright (c) 2020 by The American Association for Thoracic Surgery

https://doi.org/10.1016/j.jtcvs.2020.12.013
}

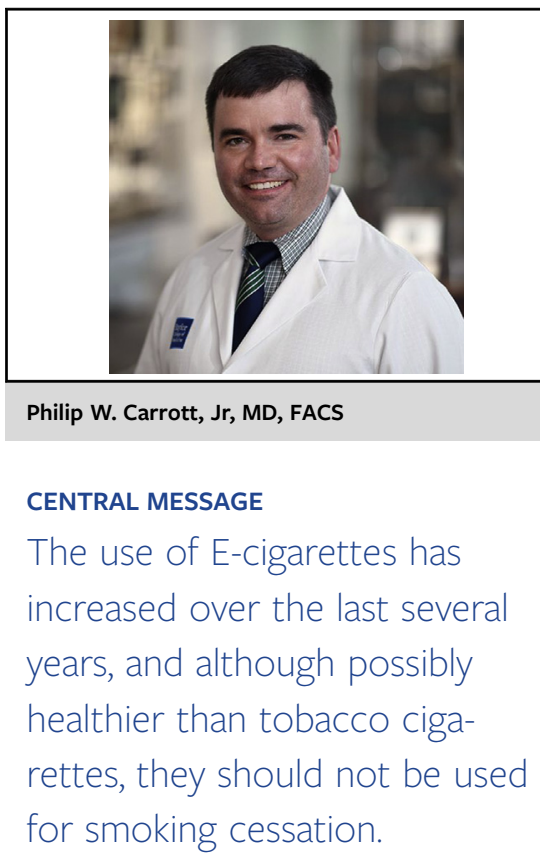

One recent article relevant to the convergence of combustible cigarettes and vapor or e-cigarettes examined the effects if one or both on the lungs and consequently on physical fitness. ${ }^{3}$ The public health branch of the US Army published a paper just before the COVID-19 outbreak describing a stepwise decrease in mean physical functioning in healthy soldiers depending on their use of cigarettes, e-cigarettes, or both. The soldiers who used both had an additive deficiency in 2-mile run time and the maximum number of push-ups and sit-ups performed in 2 minutes. Interestingly, baseline numbers in users of only e-cigarettes were worse than those of cigarette-only smokers, indicating that the short-term effects of e-cigarettes may actually be more harmful than those of cigarettes.

As a specialty, we should collectively do a better job in counseling our patients to quit smoking. One question that should be answered with a resounding "no" is: "can e-cigarettes help me quit smoking?" They may help a person transition away from smoking but are not designed with health in mind.

\section{References}

1. Steliga MA. Health hazards of electronic cigarettes and their utility in smoking cessation. J Thorac Cardiovasc Surg. 2022;163:307-10.

2. Tiku N. Startup behind the Lambo of vaporizers just launched an intelligent e-cigarette. The Verge. 2015. Available at: https://www.theverge.com/2015/ 4/21/8458629/pax-labs-e-cigarette-juul. Accessed December 20, 2020.

3. Dinkeloo E, Grier TL, Brooks RD, Jones BH. Vaping, smoking, and the physica fitness of active young men. Am J Prev Med. 2020;58:e31-7. 